\title{
EL PATRIMONIO HISTÓRICO EDUCATIVO A TRAVÉS DE LAS FOTOGRAFÍAS: LA HISTORIA DE LA EDUCACIÓN FÍSICA EN MÉXICO
}

\author{
Mónica Lizbeth Chávez González \\ mchavez@enesmorelia.unam.mx \\ Eugenia Macías Guzmán \\ eugenia.macias@gmail.com
}

\begin{abstract}
RESUMEN
El patrimonio histórico educativo es una perspectiva de análisis que permite proteger y conservar elementos materiales y culturales dentro de los procesos educativos a lo largo del tiempo. Permite reflexionar sobre el valor histórico de los objetos, prácticas y representaciones presentes en el espacio escolar desde un diálogo presente- pasado. También facilita la construcción de una memoria colectiva que refuerza la identidad social. En este texto mostraremos el proceso de montaje de una exposición fotográfica en el campo de la historia de la educación física en México que contribuye al rescate, estudio y difusión de las prácticas y discursos plasmados en la memoria colectiva en el ámbito educativo, y como tal, forma parte del patrimonio histórico educativo.
\end{abstract}

Palabras claves: Patrimonio histórico educativo. Educación Física. Exposición fotográfica

\section{THE HISTORICAL EDUCATIONAL PATRIMONY THROUGH PHOTOGRAPHS: THE HISTORY OF PHYSICAL EDUCATION IN MEXICO}

\begin{abstract}
The historical patrimony of education is a perspective of analysis that allows to protect and conserve material and cultural elements within the educational processes over time. It allows reflecting on the historical value of the objects, practices and representations present in the school space from a present-past dialogue. It also facilitates the construction of a collective memory that reinforces the social identity. In this text we will show the assembly process of a photographic exhibition in the field of the history of physical education in Mexico that contributes to the rescue, study and diffusion of the practices and discourses embodied in the collective memory in the educational field, and as such, is part of the historical patrimony of education.
\end{abstract}

Keywords: Historical patrimony of education. Physical education. Photographic exhibition

\section{O PATRIMÔNIO HISTÓRICO EDUCATIVO ATRAVÉS DE FOTOGRAFIAS: A HISTÓRIA DA EDUCAÇÃO FÍSICA NO MÉXICO}

\section{RESUMO}

O patrimônio histórico-educacional é uma perspectiva de análise que permite proteger e conservar elementos materiais e culturais dentro dos processos educacionais ao longo do tempo. Permite refletir sobre o valor histórico dos objetos, práticas e representações presentes no espaço escolar a 
partir de um diálogo presente-passado. Também facilita a construção de uma memória coletiva que reforça a identidade social. Neste texto, mostraremos o processo de montagem de uma exposição fotográfica no campo da história da educação física no México, que contribui para o resgate, estudo e difusão das práticas e discursos incorporados na memória coletiva no campo educacional e, como tal, , faz parte do patrimônio histórico educacional.

Palavras-chave: Patrimônio histórico educacional. Educação Física. Exposição fotográfica

\section{LE PATRIMOINE ÉDUCATIF HISTORIQUE À TRAVERS DES PHOTOGRAPHIES: L'HISTOIRE DE L'ÉDUCATION PHYSIQUE AU MEXIQUE}

\section{RÉSUMÉ}

Le patrimoine éducatif historique est une perspective d'analyse qui permet de protéger et de conserver les éléments matériels et culturels au sein des processus éducatifs au fil du temps. Il permet de réfléchir sur la valeur historique des objets, des pratiques et des représentations présents dans l'espace scolaire à partir d'un dialogue passé-présent. Cela facilite aussi la construction d'une mémoire collective qui renforce l'identité sociale. Dans ce texte, nous montrerons le processus d'assemblage d'une exposition photographique dans le domaine de l'histoire de l'éducation physique au Mexique qui contribue au sauvetage, à l'étude et à la diffusion des pratiques et discours incarnés dans la mémoire collective dans le domaine éducatif., fait partie du patrimoine historique éducatif.

Mots-clés: Patrimoine historique éducatif. Éducation physique. Exposition photographique.

\section{LA FOTOGRAFÍA HISTÓRICA COMO PATRIMONIO HISTÓRICO EDUCATIVO}

Desde hace varios años, las huellas del pasado en la educación están comenzando a revalorizarse como parte del patrimonio histórico. En este texto, daremos cuenta del montaje de una exposición fotográfica en el campo de la historia de la educación física en México que contribuye al rescate, estudio y difusión de las prácticas y discursos plasmados en la memoria colectiva en el ámbito educativo, y como tal, forma parte del patrimonio histórico educativo. Dicha exposición fotográfica se tituló Higiene escolar: cuerpo, moralidad, género y educación y fue montada en marzo de 2016 en la Escuela Nacional de Estudios Superiores de la Universidad Nacional Autónoma de México campus Morelia. El concepto de patrimonio nos remite a un esfuerzo de ciertos sectores de la sociedad por proteger y conservar elementos materiales y culturales que representan un valor histórico-social. Bajo esta perspectiva se ha aceptado la importancia de conservar no sólo los elementos tangibles sino los intangibles, es decir aquellos 
elementos culturales que representan modos de ser y que se convierten en aportaciones singulares a la cultura universal (Ossenbach, 2010).

En la actualidad existen políticas públicas y organismos internacionales encargados de definir y resguardar el patrimonio. Como señala Velasco, el concepto de patrimonio se ha logrado instalar en la sociedad civil tras una larga historia de esfuerzos para producir una sensibilidad y revalorización del pasado, ante lo cual se logró el involucramiento de las instituciones públicas para proteger y conservar los objetos materiales y culturales para darles perdurabilidad en un contexto social regido predominantemente por la idea del cambio (Velasco, 2007). No obstante, en el campo de la educación aún falta mucho por hacer; más allá de los esfuerzos y preocupaciones de la comunidad académica especializada en la historia de la educación, aún no existe un marco legal que defina o proteja estas huellas educativas.

Para los especialistas, pensar en el patrimonio histórico educativo implica ir detrás de artefactos culturales que no son simples objetos dignos de ser expuestos en un museo, sino que son vistos como constructos culturales, como parte de la cultura material de una sociedad que fueron producidos en un contexto social e histórico determinado. El patrimonio también es un recurso de la memoria colectiva, que representa los discursos e imaginarios materializados en los proyectos educativos y, que como tal, forma parte de la identidad social. Al considerarlo como un elemento de la memoria colectiva, asumimos que el patrimonio escolar refleja las formas de vida y de pensamiento de una sociedad: anhelos, ideología, normas, valores, actitudes, resistencias, conocimientos, formas de comunicación, relaciones sociales, entre otras.

El patrimonio histórico es un recurso que además facilita el proceso educativo, ya que también es una herramienta pedagógica que permite un diálogo presente-pasado a partir de artefactos y prácticas que posibilitan una reflexión crítica de los procesos escolarizados. Es por ello que la lectura pedagógica del patrimonio escolar debe de ser acompañada indispensablemente de una contextualización histórica que permita entender a los objetos materiales e inmateriales como situados en un entorno cultural e histórico específico. El patrimonio histórico escolar es un recurso que nos obliga a pensar de manera reflexiva y crítica el pasado, a considerar qué valores, conocimientos y prácticas se han llevado por el sendero de la institucionalización mientras que otros han quedado fuera de la esfera político-educativa. Considerar a las imágenes como un patrimonio histórico cultural nos obliga a enmarcarlas en un contexto de producción específico que 
refleja la ideología y los anhelos de un sector político en búsqueda de una construcción ciudadana (ESCOLANO; MARTI; OSSENBACH, 2009).

Las fotografías son una huella de la cultura escolar de ahí que puedan considerarse como parte del patrimonio histórico educativo. En cierto sentido, las fotografías son textos que ofrecen una lectura detallada del universo cultural escolar y son una muestra de la memoria colectiva. $\mathrm{Su}$ conservación es fundamental porque no sólo son una huella del pasado, sino que son una fuente valiosísima para el análisis de las subjetividades y de la materialidad de las escuelas.

En términos de los procesos comunicativos y expresivos propios de la fotografía, la riqueza de su valor testimonial que facilita procesos de construcción de memoria, no reside tanto en la resolución visual que se aprecia de esta disciplina y sus productos, y que se reafirmó con sus usos sociales en sus orígenes como herramienta de registro "fiel u objetiva con lo real". Esta nitidez es sólo la puerta de entrada a fenómenos de construcción de lo significativo que ocurren en lo que despliegan las imágenes fotográficas, pero no en lo aparente en ellas, sino en las asociaciones con otros puentes de significado que eso visible dispara en uno al contemplarlas. Esto es lo que constituye el valor testimonial de lo fotográfico: un dispositivo que permite pensar histórica e interpretativamente los sucesos que registra. Fue posible plantear esto como vía de conocimiento a través de lo visual cuando cambió el estatuto de la imagen, que de ser presencia de un fragmento o detalle del mundo afuera, transitó a ser un dispositivo de estudio, investigación y análisis. La historia misma de los usos de lo fotográfico da cuenta de esta transición (RONSENBLUM, 1989).

Cuando se inicia una búsqueda de este tipo en las imágenes, la observación suele ser prolongada, atenta, detenida, intencional, no desinteresada (uno va buscando cosas). Pero mirar así debe ser lo más flexible posible para permitirse hallazgos que una contemplación rígida inhibiría. El abordaje interdisciplinario resulta fundamental para potencializar las miradas reflexivas sobre las imágenes, en este caso, se realizó un diálogo entre la Historia y la Historia del Arte.

La Historia del Arte opera con la descripción de las obras como una de sus principales herramientas metodológicas, una vía para organizar y explicitar el pensamiento de la mirada sensible. Describir en este sentido, no se limita a enumerar o enlistar lo aparente, sino a preguntar cosas, problematizar, indagar y documentar este camino en la escritura, estableciendo vínculos entre lo denotado y lo connotado de los rasgos que uno señala en lo visual (BAXANDALL, 1989, p. 15-26; BARTHES, 1982, p. 63-70, p. 89-93). Esto atraviesa también a la fotografía como una disciplina visual susceptible de ser estudiada con la Historia del Arte. 
Es esta riqueza interpretativa la que ofrece a plenitud lo fotográfico, pues da acceso a distintos procesos sociales alojados en la visualidad misma de las imágenes. Historiar con ellas, implicaría un ejercicio de antropología visual: detectar a través de los rasgos aparentes diversas dinámicas sociales, culturales, política y económicas, señaladas como índices en las fotografías (BENJAMIN, 1973, p. 31-35; HANNERZ, 1992, p. 7-17; RISSEEUW, 2006, p. 157-182) para ser luego tratados a mayor profundidad con otras técnicas de investigación documental y testimonial que exige una perspectiva interdisciplinaria que combine herramientas de diversas áreas humanísticas y sociales.

\section{CÓMO SURGIÓ LA EXPOSICIÓN FOTOGRÁFICA}

La exposición fotográfica Higiene escolar: cuerpo, moralidad, género y educación surge en el marco de un proyecto de investigación que tiene como principal objetivo analizar las configuraciones de género plasmadas en la ejercitación corporal de las mujeres a través de la introducción de la educación física en las escuelas en el tránsito del siglo XIX al XX en México. Específicamente se analizaron los debates y justificaciones que evidenciaban el interés del Estado mexicano por moldear el cuerpo de sus ciudadanos bajo premisas que de manera implícita reforzaban los estereotipos tradicionales sobre el deber ser de las mujeres a la vez que generaba nuevas representaciones de la mujer moderna y de sus cuerpos. Primero bajo un discurso modernizador y posteriormente bajo la bandera del nacionalismo, el Estado mexicano a través del currículum escolar pretendió moldear las actitudes corporales de los y las mexicanas para construir una ciudadanía no exenta de diferencias y desigualdades sexistas (CHÁVEZ, 2009, 2009a, 2015).

$\mathrm{Al}$ analizar la introducción de la educación física en el currículo escolar se logró entender el papel que juegan las escuelas en la formación cotidiana del poder político de los EstadosNacionales. En esta investigación partimos de la idea de que la escuela es un espacio de socialización que no únicamente transmite conocimiento teórico, sino valores morales y símbolos implícitos -en este caso en torno al cuerpo y el género- presentes en la selección y presentación del conocimiento práctico, como lo fue la educación física (ROCKWELL, 1995). En este caso, las escuelas contribuyeron a la conformación de representaciones corporales basadas en la diferencia anatómica y sexual que transformaban pero también reforzaban estereotipos de género. En el tránsito del siglo XIX al XX el cuerpo femenino y su ejercitación fue tema de diferentes discursos 
-médico, pedagógico, higiénico, eugenésico, nacionalista- dentro de los cuales las diferencias anatómicas y fisiológicas que resaltaban la función reproductora femenina fue el punto central en la definición de las relaciones de género.

Al historiar las representaciones en torno al cuerpo femenino en la educación física demostramos que los límites trazados para la ejercitación física provinieron de una visión androcéntrica que naturalizó un discurso de poder que jerarquizaba el papel social de las mujeres mexicanas de la época. A nombre de la ciencia y la unidad nacional, los políticos y pedagogos mexicanos - varones en su mayoría- enarbolaron discursos que definieron y naturalizaron una serie de valores y símbolos al cuerpo femenino que los colocaba en una posición no solo de diferencia sino de desigualdad.

Desde finales del siglo XIX las escuelas mexicanas, la mayoría de ellas ubicadas en las ciudades del país, iniciaron un proceso de modernización producto de la nueva política educativa que puso mayor atención a la transmisión de conocimientos útiles para el progreso material y la unidad nacional. En este contexto, los políticos porfiristas elaboraron diversas reformas curriculares acorde con las ideas pedagógicas de la llamada escuela nueva o moderna. La gimnasia escolar -como se le llamó al inicio- o la educación física comenzó su incorporación en los planes curriculares de las escuelas urbanas mexicanas acompañada de una serie de discursos sobre el deber ser del hombre y la mujer en tanto debían ser futuros ciudadanos.

El Estado liberal mexicano se concibió a sí mismo como un agente educador interesado no sólo en enseñar contenidos teóricos formales, sino en moldear los comportamientos y las subjetividades de los escolares. El cuerpo de hombres y de mujeres, se convirtió para los políticos y pedagogos en un elemento de aprendizaje y en un dato de la anhelada modernidad, ya que debía transmitir una serie de valores y símbolos que definían la relación del Estado con sus ciudadanos: como la disciplina, el vigor, la fuerza para el caso de los varones; y la delicadeza, la gracia, la belleza, para el caso de las mujeres.

La intervención del Estado mexicano en los cuerpos de sus ciudadanos fue incrementándose en los primeros años de la posrevolución mexicana. Una muestra de ello fue la institucionalización y difusión de la educación física al momento de crear la Secretaría de Educación Pública (SEP) en 1921 e iniciar la masificación educativa (VAUGHAN, 2000). El Estado posrevolucionario invirtió recursos económicos y políticos para crear un departamento administrativo, una escuela especializada y varios estadios deportivos en el país. Los cuerpos de hombres y mujeres 
ejercitándose mediante tablas gimnásticas se incluyeron dentro de los rituales políticos que exhibían el ferviente nacionalismo al conmemorar las festividades patrióticas. En este contexto, los sentidos culturales otorgados al cuerpo femenino presentaron continuidades con respecto al porfiriato pero también construyeron imágenes idealizadas basadas en modelos griegos y estadounidenses insertos en una política de regeneración nacional propia del ambiente posrevolucionario.

Los funcionarios de la SEP dieron continuidad a las ideas porfiristas de finales del siglo XIX al considerar a la educación física como uno de los principales medios para reconstruir a la población mexicana: debía regenerar biológica y estéticamente a la raza mexicana, civilizar las costumbres a través de la higiene corporal, inyectar mayor vitalidad y energía al cuerpo para aumentar el rendimiento laboral y transmitir ciertos valores morales como la competitividad, solidaridad, disciplina, el refuerzo de la voluntad, entre otros.

Para llegar a estos hallazgos esta investigación se consultaron diversas fuentes de información: documentos educativos oficiales (manuales, reglamentos, leyes, informes, programas escolares, expedientes laborales), algunos medios de difusión masiva a nivel nacional (prensa y revistas pedagógicas), las imágenes relacionadas con la educación física (fotos, carteles y litografías) y algunos archivos sensibles (la literatura y testimonios de mujeres). Todas estas fuentes nos acercaron al universo simbólico y normativo presente en la ejercitación física de las mujeres en las escuelas; no obstante, las imágenes y fotografías se convirtieron en un elemento central de la investigación en tanto nos mostraban no sólo los discursos o a las representaciones, sino a las prácticas y sus escenarios en el mundo rural y campesino.

Las imágenes y fotografías históricas sobre la educación física en México se obtuvieron de diferentes repositorios documentales. Para finales del siglo XIX se obtuvieron principalmente litografías presentes en los manuales escolares en donde las imágenes servían para ejemplificar los ejercicios descritos así como para representar los cuerpos imaginarios. Estos manuales se obtuvieron en librerías de viejo o en tianguis de antigüedades. Algunos otros fueron consultados en la Biblioteca Nacional. Para las primeras décadas del siglo XX se consultó el Archivo Histórico de la Secretaría de Educación Pública (AHSEP), la Hemeroteca Nacional y la Biblioteca Nacional. En el AHSEP se consultó el Fondo de Misiones Culturales, en donde se encontraban expedientes de cada una de las Misiones y de los Institutos Sociales que se fundaron a lo largo y ancho del país para cumplir el llamado de José Vasconcelos de llevar a cabo una “cruzada contra la ignorancia” e 
incorporar a los indígenas y campesinos al proyecto de nación civilizada (RAMÍREZ, 1927, SANTIAGO, 1974, LOYO, 1999). A estas misiones llegaba un maestro responsable de la misión, una trabajadora social, un profesor de agricultura, otro de pequeñas industrias y otro de educación física. Éste último se encargaba de la organización del evento de clausura de la Misión, en el cual no podían faltar exhibiciones gimnásticas o competencias deportivas, mismas que quedaron registradas en las fotografías. Es por ello que las fotografías deportivas que conformaron esta exposición fotográfica provienen del trabajo de los profesores de educación física en las Misiones Culturales en diferentes regiones del país entre 1926 y hasta 1934.

Buena parte de las imágenes de esta exposición provienen de la Revista de Educación Física ubicada en la Biblioteca Nacional. Esta revista se difundió por primera vez en 1923, en los años en los que José Vasconcelos fundó el Departamento de Educación Física en la SEP, la Escuela Elemental de Educación Física -la primera institución formadora de maestros en esta disciplina- y construyó espacios amplios para la práctica de deportes, torneos y exhibiciones. Esta revista, que tuvo una vida muy corta, integró a pedagogos, políticos e intelectuales mediante diversos artículos de información y difusión deportiva combinados con artículos de corte literario, filosófico y plástico que exaltaban el culto al cuerpo y al nacionalismo mexicano.

La exposición Higiene escolar: cuerpo, moralidad, género y nación formó parte del curso Taller de Crítica y Curaduría impartido en los semestres tercero y cuarto de la segunda generación de la Licenciatura en Historia del Arte de la Escuela Nacional de Estudios Superiores de la UNAM en Morelia en los semestres 2016-1 y 2016-2. La investigación documental y de materiales fotográficos aquí narrada, constituyó un caso práctico que fue herramienta pedagógica de dicha asignatura. Se comenzó con la revisión de imágenes recabadas en esta investigación y su agrupamiento por ejes temáticos o núcleos, que es la manera de nombrarlos en el lenguaje especializado de la museología, disciplina que problematiza e indaga sobre procesos comunicativos, sociales, económicos, políticos y culturales involucrados en los espacios y actividades de museos y otros recintos socializadores y educativos.

A estos temas, también se les nombra núcleos en la curaduría, ámbito profesional especializado dedicado actualmente a la investigación y diseño de contenidos e información de exposiciones y cualquier otra salida comunicativa, aplicada y de difusión social de conocimiento especializado, como ediciones, materiales sonoros, montajes escénicos, etc. 
La curaduría comenzó con la apertura pública de colecciones privadas y la creación y concepción de los primeros museos en Europa desde el siglo XVIII, como una actividad encaminada a estar a cargo del cuidado de un acervo y sus modos de exhibición. Actualmente en el ámbito de museos y espacios de exposición de objetos, además de este ámbito de "cuidar" es una actividad reflexiva-interpretativa que ejerce una mediación entre los mensajes que portan los objetos exhibidos y el público que los contempla durante su visita a una exposición. Esto implica que el curador asuma posicionamientos analíticos y epistemológicos respecto al grupo de materiales que decide exhibir y distribuir en un espacio para estos fines.

Estas posturas que pueden ser de índole teórica, política o de aplicación de corrientes y avances en distintas disciplinas, exigen una investigación sobre el grupo de objetos seleccionados para ser exhibidos, el diseño de un planteamiento central que articule y ramifique una estructura por núcleos o temas, que luego son traducidos a la colocación de los objetos en una sala de exhibición. La cuestión central es la intención decidida de proponer lecturas específicas o énfasis de la realidad y al mismo tiempo permitir espacios para que el espectador construya desde su apreciación su propio diálogo con los materiales expuestos (GLEADOWE, 2003, p. 33-39; SUAZO, 2003, p. 78-81; HERNÁNDEZ, 2006, p. 197-226).

Es así que a partir de estas premisas del trabajo curatorial, y de las herramientas descriptivas visuales de la Historia del Arte señaladas en páginas anteriores de este texto, al observar cuidadosamente y discutir colectivamente estudiantes y profesores los rasgos de cada imagen, se propusieron tres núcleos o temas y se clasificaron las fotografías en cada uno de ellos basándose en la correspondencia entre imagen y tres ejes de reflexión identificados como las líneas predominantes de agrupamiento de las fotografías para su distribución en el espacio de la exposición:

1. El cuerpo como repositorio de valores morales.

2. Ficciones de cuerpo y género.

3. Cuerpo y nación.

Para fines prácticos pedagógicos el grupo de estudiantes se dividió en 3 equipos. Cada uno generó el texto de cada núcleo, presentó al grupo y profesores una primera versión que se modificó colectivamente considerando criterios de brevedad, síntesis y divulgación en sus rasgos finales. Cada equipo también elaboró las cédulas de cada obra en su núcleo y fichas explicativas en aquellas en que era necesario señalar información adicional y se hizo cargo del montaje en el área 
correspondiente a cada núcleo en la primera sede de la exposición en el Centro Cultural UNAM Morelia en febrero de 2016. Hubo una segunda exhibición en el marco del XIV Encuentro Internacional de Historia de la Educación realizado en Aguascalientes, México en noviembre del 2016 implementada por Mónica Lizbeth Chávez González creadora de esta investigación y coautora de este artículo.

Una primera fase del montaje es la producción de los textos a muro, cédulas y fichas. Después se realiza la presentación de las obras en el espacio de la exposición, el pasillo principal exterior del Centro Cultural UNAM Morelia en mamparas portátiles de madera expuesta (las obras en este caso fueron reproducciones tamaño tabloide, cada una en una lámina plástica resistente a intemperie a partir de digitalizaciones de las fotografías de época originales), para calcular su distribución en el espacio expositivo y la circulación del público a través de éste y de la estructura reflexiva y narrativa curatorial. Finalmente se realizó el fijado de las obras en mamparas.

El núcleo 1, El cuerpo como repositorio de valores morales, agrupó obras como textos ilustrados con modos de ejercitarse, cuidar el cuerpo y advertencias de consecuencias de ignorar estas premisas y obras fotográficas, cuya visualidad connotaba la educación física como estrategia de Estado para promover salud pública, renovación racial y disciplina moral (valores como responsabilidad, compromiso, participación, unidad, equipo, solidaridad).

En el núcleo 2, Ficciones de cuerpo y género, se agruparon obras que registrando eventos en contexto rural o urbano, remitían a definiciones de roles de género a través de prácticas como ejercicios dancísticos que acentuaban la delicadeza, capacidad de procreación y de mejoramiento de la raza en las mujeres, y movimientos y dinámicas grupales que enfatizaban la fuerza, ciudadanía, disciplina y trabajo en los hombres. En algunas obras se explicitaron referentes a la Antigüedad grecorromana presentes en manuales educativos de higiene y cuerpo aludiendo a figuras como bailarinas o guerreros de esa época, para definir roles de fuerza y belleza.

En el núcleo 3, Cuerpo y nación, se eligieron obras que documentan dinámicas de institucionalización de la educación física, testimonios visuales de exhibiciones deportivas y físicas, implementadas por profesores que la SEP enviaba a comunidades urbanas y rurales y dónde se convirtieron en especies de etnógrafos de los lugares donde eran comisionados. Este núcleo da cuenta de eventos públicos de higiene física institucionalizados por el Estado y el partido oficial (PNR hacia la década de 1930) del que el ejemplo más elocuente y actual es el desfile de conmemoración del XX aniversario de la Revolución Mexicana. 
Se decidió hacer fichas explicativas complementarias a ciertas imágenes en cada núcleo por la carga de significación o información del tema tratado en algunas fotografías. A continuación se presentan las obras que integraron cada núcleo y dos ejemplos por núcleo de fichas explicativas complementarias. Las cédulas que datan cada pieza, están presentadas aquí como pies de figura.

\section{Núcleo 1. El cuerpo como repositorio de valores morales}

Figura 1: Alberto D. Landa, Tratado elemental de gimnástica higiénica y pedagógica, 1894, México, Gallegos Hermanos, Libreros Editores, Impresión litográfica y fotomecánica, 40.5 x $50.5 \mathrm{~cm}$.

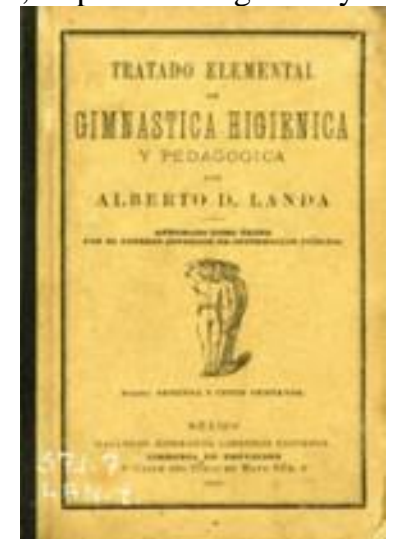

Fuente: Col. Biblioteca Nacional de México-UNAM.

Figura 2: José de Jesús González, Higiene escolar (portada), 1918, México, Librería de la Viuda de Ch. Bouret, Reproducción, 40.5 x $50.5 \mathrm{~cm}$.

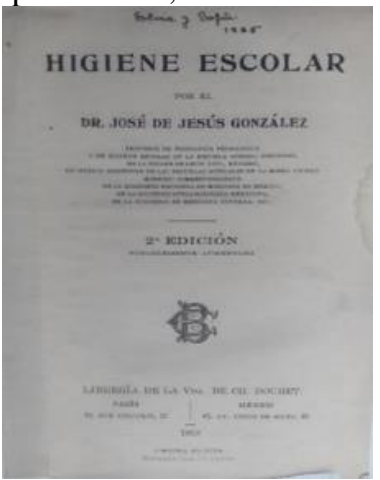

Fuente: Original conservado en la Biblioteca Nacional de México.

\section{Ficha Explicativa: Manuales}

Durante el siglo XIX en México se enseñó que "si para los antiguos la higiene era el arte de conservar la salud, para los 'modernos' era la ciencia que trata de la salud o la fisiología 
aplicada". La higiene fue un tema del Viejo Mundo adoptado por la ciencia occidental amalgamado al nuevo proceso de industrialización.

El gobierno mexicano promovió la idea de una civilización basada en el progreso, motivo por el cual -vinculado a un desarrollo de tipo capitalista- la higiene tenía que ver con prácticas al modo occidental para establecer distinciones sociales. En México algunos de los libros de texto para enseñar los principios de la higiene fueron: el Tourtelle, el Briand, el Becquerel, el Lacassagne y Proust. Alberto D. Landa crea en 1894 (1884) el Tratado Elemental de Gimnástica Higiénica y Pedagógica, el cual surge como el primer libro de texto elaborado por un mexicano en el mismo territorio.

El Dr. José de Jesús González fue un médico oftalmólogo activo en la ciudad de León, Guanajuato, interesado en destacar la relación entre la salud y el aprendizaje de los niños, que le llevó a publicar la primera edición del libro Higiene escolar en 1910, una segunda edición en 1918 y una tercera en 1927 dirigido a los maestros de las escuelas en la República Mexicana así como en Sudamérica. En 1929 y 1930, se hizo acreedor a una medalla de oro y un diploma otorgados por la Feria Iberoamericana llevada a cabo en Sevilla.

Figura 3: Sin autor, (Jóvenes practicando vóleibol), Villa Jiménez, Durango, 1927, Reproducción, 40.5 x 50.5 cm.

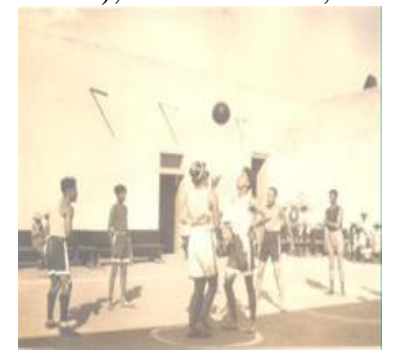

Fuente: Original conservado en el Archivo Histórico de la Secretaría de Educación Pública.

Figura 4: Educación Física, no. 2, “Los Diablitos” de la Escuela Nacional Preparatoria (una página), Dirección de Educación Física - SEP, 1923, Reproducción, 40.5 x 50.5 cm.

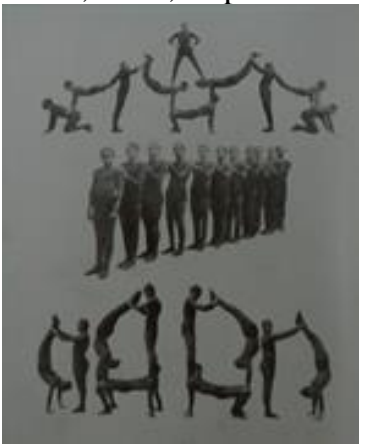

Fuente: Original conservado en la Hemeroteca Nacional, UNAM 


\section{Ficha Explictiva: Los Diablitos}

Durante la posrevolución se abrió paso a la idea de la unidad nacional, ya que como práctica de socialización el deporte aglutinaba a varios sujetos para realizar trabajo en equipo y resaltaba actitudes de unidad, solidaridad y disciplina entre los participantes.

Al convertir estas competencias deportivas en espectáculos públicos, las escuelas se encargaron de promover un discurso sobre el atleta-ciudadano que se integraba al trabajo colectivo para lograr un bien común, aspectos centrales para la propagación del nacionalismo de la época.

Figura 5: Sainz, Ejercicios de gimnasia respiratoria (una página), 1898, Reproducción, 40.5 x 50.5 cm.

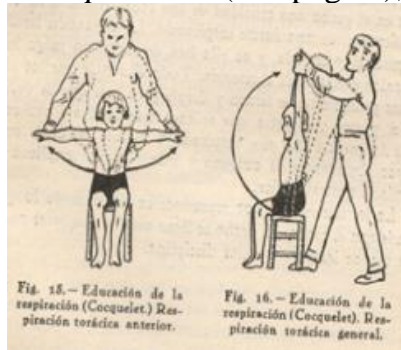

Fuente: Original conservado en la Biblioteca Nacional de México.

Figura 6: E. Caustier, Buenas y malas actitudes estando sentado (una página). Historia Natural aplicada, Dr. Jesús Díaz de León (trad.), México, Ed. Vda. Ch. Bouret 1927, Reproducción, 40.5 x $50.5 \mathrm{~cm}$.

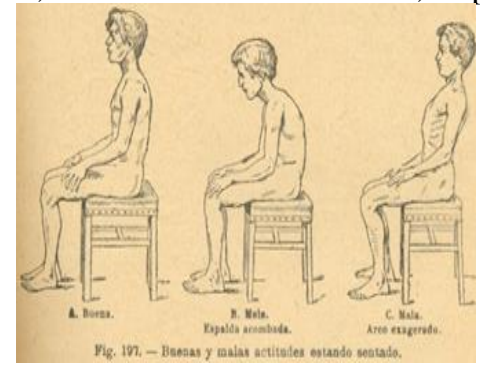

Fuente: Original conservado en Biblioteca Particular. 
Figura 7: Educación Física, no. 1, Ejercicios para los perezosos (una página), Dirección de Educación Física - SEP, 1923, Reproducción, 40.5 x $50.5 \mathrm{~cm}$.

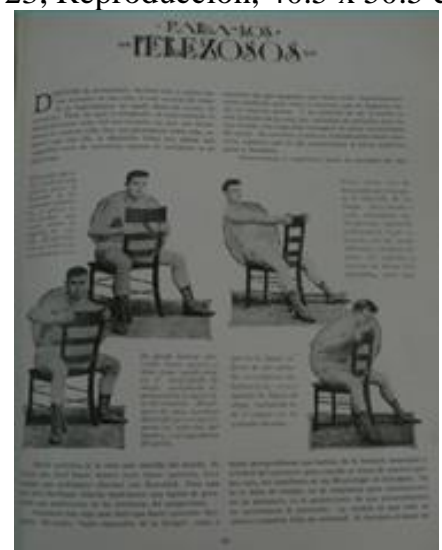

Fuente: Original conservado en la Hemeroteca Nacional, UNAM.

Figura 8: Sin autor, (Mujeres practicando pasos de baile), Sin fecha, Reproducción, 40.5 x $50.5 \mathrm{~cm}$.

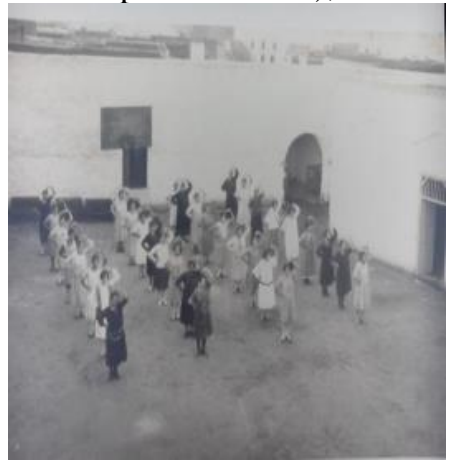

Fuente: Original conservado en el Archivo Histórico de la Secretaría de Educación Pública.

Figura 9: Sin autor, (Grupo de personas ejercitándose al aire libre), Sin fecha, Reproducción, 50.5 x $60.5 \mathrm{~cm}$.

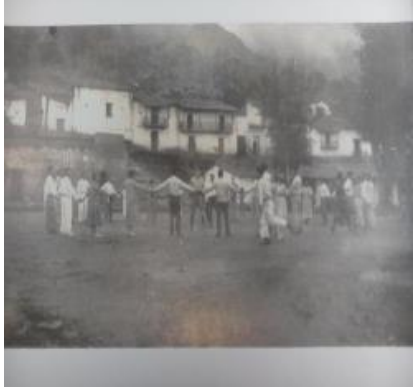

Fuente: Original conservado en el Archivo Histórico de la Secretaría de Educación Pública.

Rev. Iberoam. Patrim. Histórico-Educativo, Campinas (SP), v. 4, n. 1, p. 144-169, jan./jun. 2018 


\section{Núcleo 2. Ficciones de cuerpo y género}

Figura 10: Emma Ruiz Gimnasia Rítmica (portada), Sin fecha, Reproducción, 60.5 x 50.5 cm.

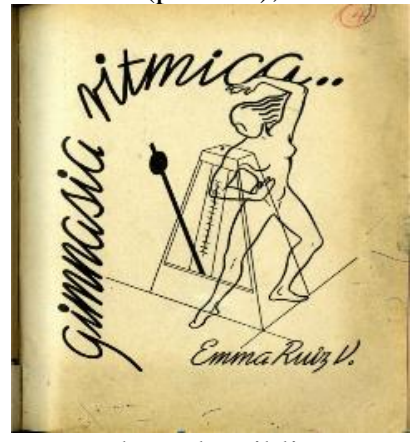

Fuente: Original conservado en la Biblioteca Nacional de México.

Figura 11: Sin autor, (Los efectos negativos del uso de corsé en las mujeres.), 1927, Reproducción, 40.5 x 50.5 cm.

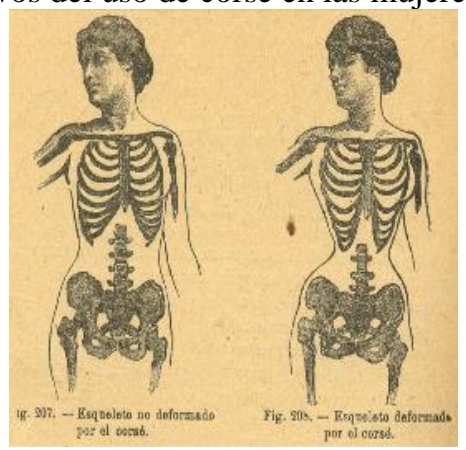

Fuente: Original conservado en la Biblioteca Nacional de México.

Figura 12: Sin autor, (Señoritas cultoras de la Educación Física y Atletas vencedores de la Escuela Nacional Preparatoria), 1923, Reproducción, 50.5 x $40.5 \mathrm{~cm}$.

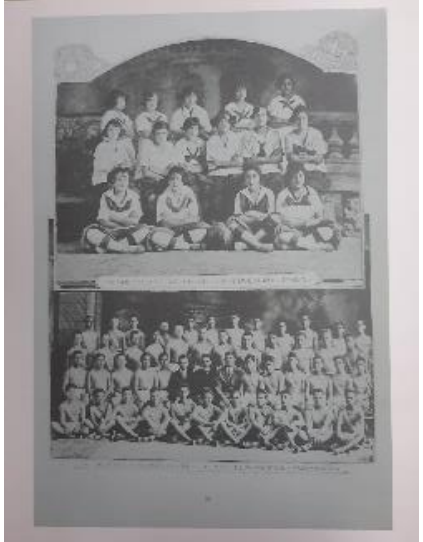

Fuente: Original conservado en la Hemeroteca Nacional UNAM. 
Figura 13: Sin autor, (Mujeres en bloomers ejercitándose), San Luis Potosí, SLP. , 1928, Reproducción, 40.5 x 50.5 $\mathrm{cm}$.

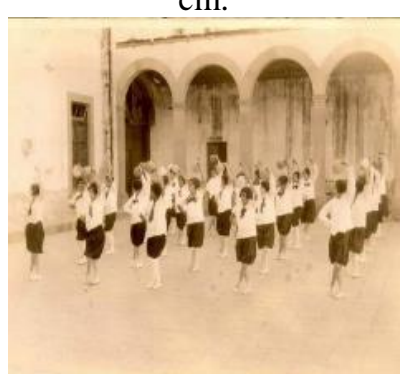

Fuente: Original conservado en el Archivo Histórico de la Secretaría de Educación Pública.

Figura 14: Sin autor, (Rutinas de ejercicios para sectores sociales incluidos en esta modernización corporal), 1923, Reproducción, 40.5 x $50.5 \mathrm{~cm}$.

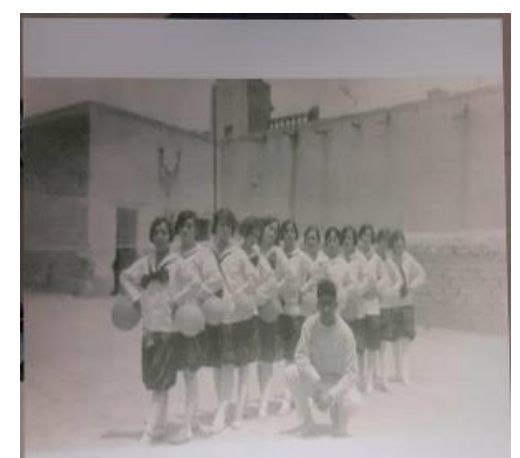

Fuente: Original conservado en el Archivo Histórico de la Secretaría de Educación Pública.

Figura 15: Sin autor, (Cartel de Gimnasia en el Hogar), 1923, Reproducción, 50.5 x 40.5 cm.

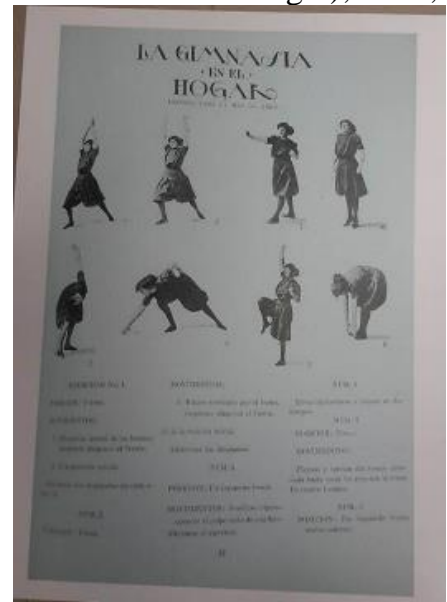

Fuente: Original conservado en la Hemeroteca Nacional UNAM.

Rev. Iberoam. Patrim. Histórico-Educativo, Campinas (SP), v. 4, n. 1, p. 144-169, jan./jun. 2018 
Figura 16: Sin autor, (Serie de ejercicios masculinos), Sin fecha, Reproducción, 40.5 x $50.5 \mathrm{~cm}$.

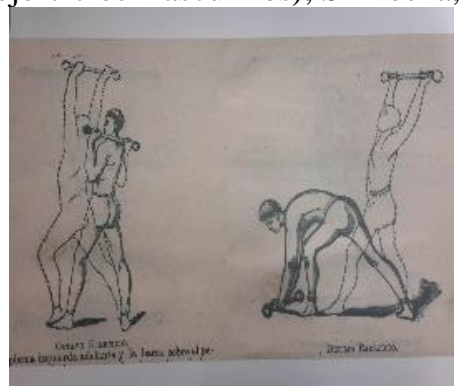

Fuente: Original conservado en la Biblioteca Nacional de México.

Figura 17: Sin autor, (Hombres ejercitándose. Ciudad de México.), 1927, Reproducción, 40.5 x 50.5 cm.

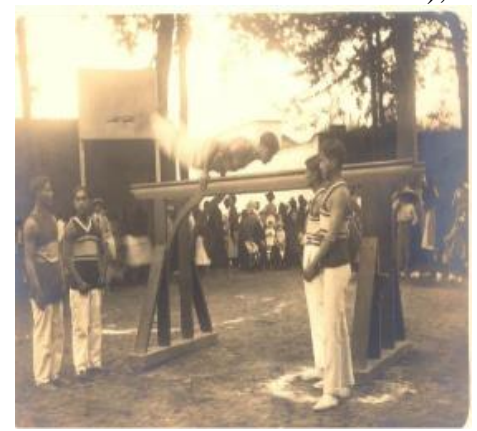

Fuente: Original conservado en el Archivo Histórico de la Secretaría de Educación Pública

Figura 18: Sin autor, (Mujeres ejercitándose. Atlacomulco), 1927, Reproducción, 40.5 x $50.5 \mathrm{~cm}$.

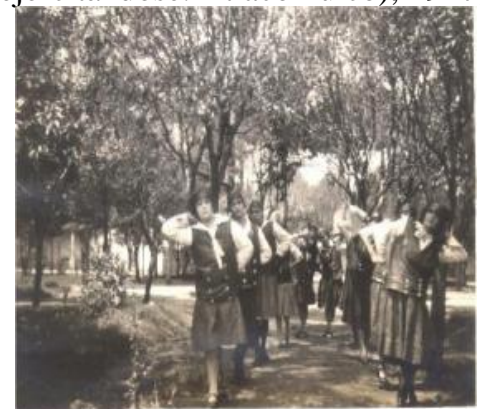

Fuente: Original conservado en el Archivo Histórico de la Secretaría de Educación Pública.

Figura 19: Sin autor, (Hombre y Piedra del Sol. Página 1), Educación Física No. 1, Dirección de Educación Física SEP, Febrero 1923, Reproducción.

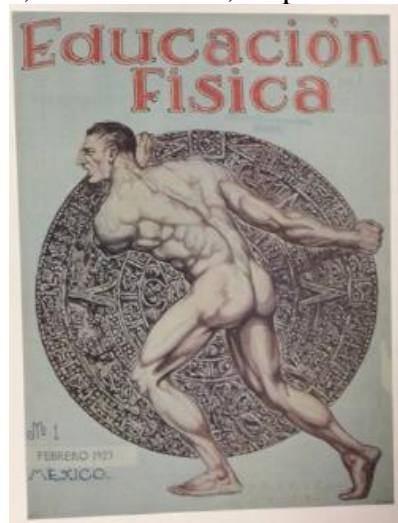

Fuente: Original conservado en la Hemeroteca Nacional, UNAM.

Rev. Iberoam. Patrim. Histórico-Educativo, Campinas (SP), v. 4, n. 1, p. 144-169, jan./jun. 2018 
Ficha Explicativa: Educación Física (Hombre con Piedra del Sol

Este hombre que aparece en la portada de la revista Educación Física recuerda a las representaciones de deportistas y guerreros que se pueden encontrar en esculturas de la Antigüedad Grecolatina: tiene gran corpulencia, sus músculos están en tensión y demuestran gran fuerza y dinamismo al momento de realizar una acción. En este caso, él emplea sus energías para mover uno de los principales símbolos del pasado prehispánico, de la identidad nacional y del cambio de ciclos: la Piedra del Sol (Cultura Mexica, posclásico tardío ca. 1502-1521. Calendario de 5 eras). Algunos ejemplos de producciones antiguas a las que remite su corporalidad son:

Figura 20: Discóbolo, copia romana del siglo II.

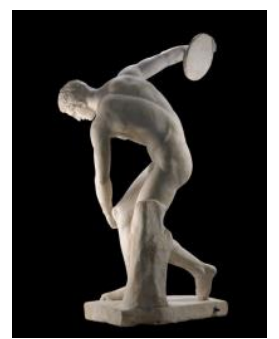

Fuente: Museo Británico.
Figura 21: Luchadores, copia de la versión romana en el Museo Uffizi, c. 1750-1800.

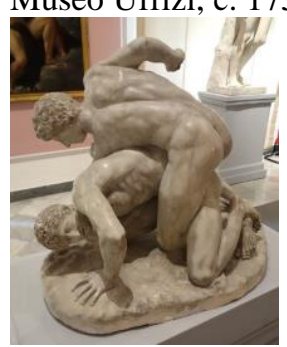

Fuente: Academia Ligústica de Bellas Artes, Génova, Italia.

Figura 22: Sin autor, (Estatuas vivientes. Página 40), Educación Física No. 1, Dirección de Educación Física - SEP, Febrero 1923, Reproducción.

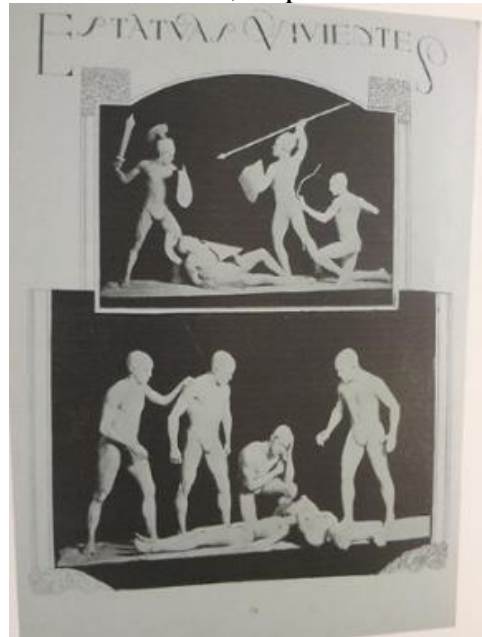

Fuente: Original conservado en la Hemeroteca Nacional, UNAM. 


\section{Ficha Explicativa, Artículo de la Revista Educación Física -Estatuas Vivientes}

La representación de fuerza, virilidad y gracia se ven reflejados en esta imagen de la revista Educación Física, que imitó elementos de iconografía grecolatina por medio de "Estatuas vivientes", estas emulaciones pueden ser comparadas con algunos objetos de la misma cultura como jarrones, vasijas y esculturas, en las cuales plasmaron escenas de hombres realizando alguna actividad identificada con su sexo (ejercitándose, combatiendo, realizando actividades artísticas, haciendo deporte, etc.), como se observa en las siguientes piezas de cerámica de la Grecia antigua.

Figura 23: Izq. Crátera columna, 600 a.C, Corintia. Der. Ánfora panatenaica,323-322 a.C., Atenas.
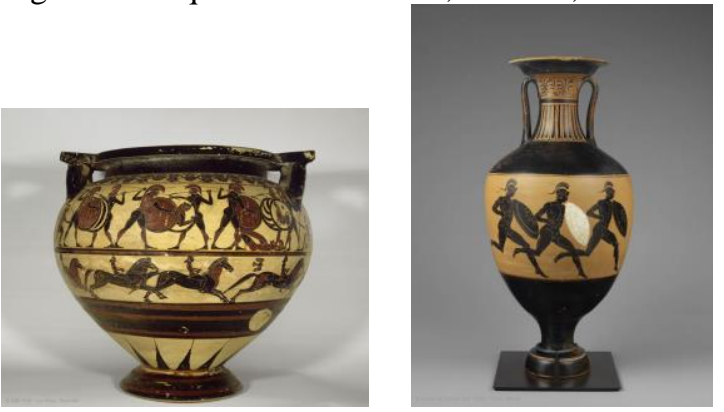

Fuente: Museo de Louvre.

Figura 24: Sin autor, (Profesores de Educación Física. Página 37), Educación Física No. 1, Dirección de Educación Física - SEP, Febrero 1923, Reproducción.

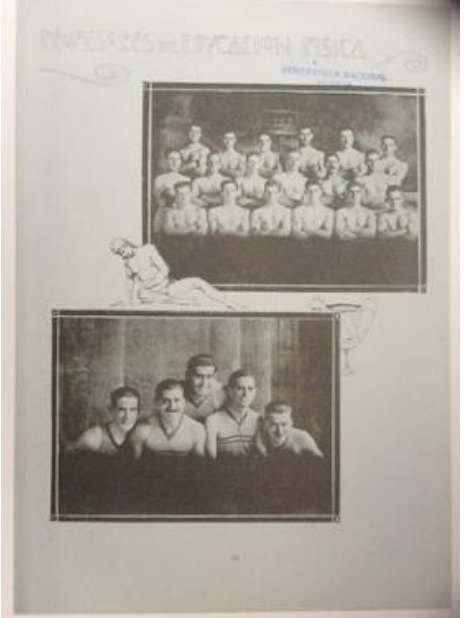

Fuente: Original conservado en la Hemeroteca Nacional, UNAM. 


\section{Núcleo 3. Cuerpo y nación}

Figura 25: Sin autor, (Tres personas, Chiapa de Corzo), 1928, Reproducción.

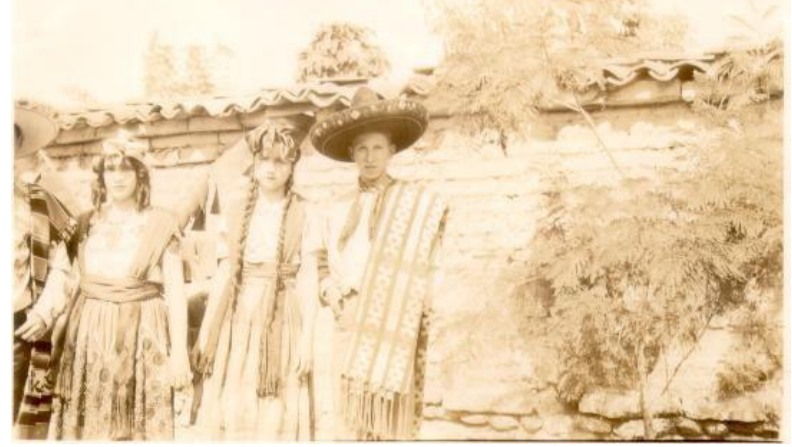

Fuente: Original conservado en el Archivo Histórico de la Secretaría de Educación Pública.

Figura 26: Sin autor, (Niño en ceremonia), 1927, Reproducción.

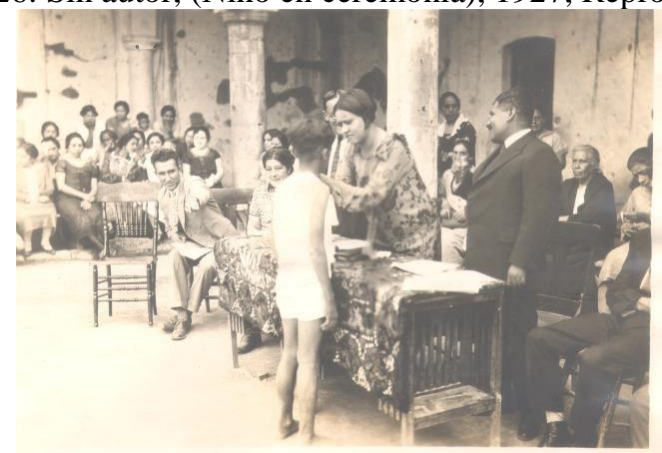

Fuente: Original conservado en el Archivo Histórico de la Secretaría de Educación Pública.

Figura 27: Sin autor, (Formación de niños, Xilitla), sin fecha, Reproducción.

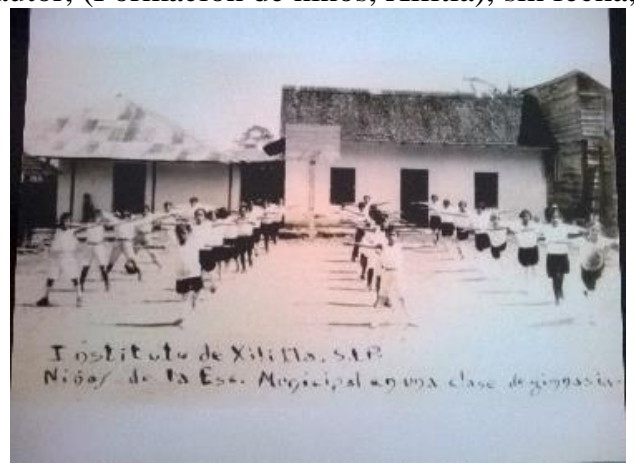

Fuente: Original conservado en el Archivo Histórico de la Secretaría de Educación Pública.

\section{Ficha Explicativa: Xilitla, SLP (Formación De Niños)}

Desde el siglo XIX se crearon escuelas en Zacatecas y San Luis Potosí, las cuales se convirtieron en espacios estratégicos de la sociedad con la ideología y política del Estado, en donde

Rev. Iberoam. Patrim. Histórico-Educativo, Campinas (SP), v. 4, n. 1, p. 144-169, jan./jun. 2018 
se intentó afirmar el espíritu social de la época por medio de los estudiantes y maestros, quienes se apropiaron de las reformas de acuerdo a su contexto. Cabe señalar que gracias a la creación de los Institutos, algunos profesores pudieron enseñar en sus propios pueblos sin tener que trasladarse forzosamente a las zonas urbanas. Uno de estos Institutos fue el de Xilitla, instalado el 22 de septiembre de 1927, cuyo sitio contó con una asistencia de 510 personas. Ubicado en dicho municipio de la región de la Huasteca, en San Luis Potosí, que deriva del náhuatl que significa "lugar de caracolillos", antes llamado Taziol, y el cual fue nombrado Pueblo Mágico en diciembre del 2011.

Figura 28: Sin autor, (Formación en Teotihuacán), 1928, Reproducción.

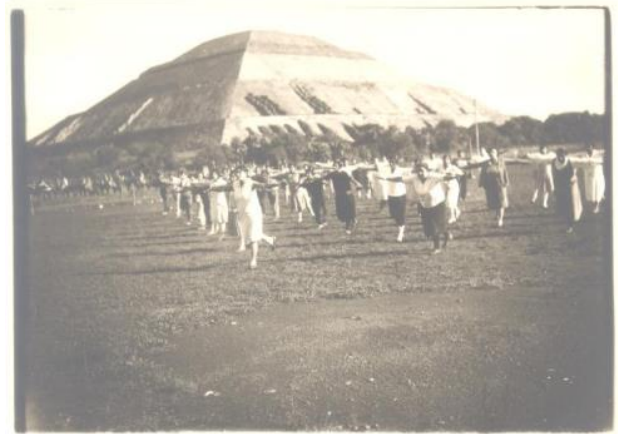

Fuente: Original conservado en el Archivo Histórico de la Secretaría de Educación Pública.

Figura 29: Sin autor, (Maestros en clase de Educación Física), s/f, Reproducción.

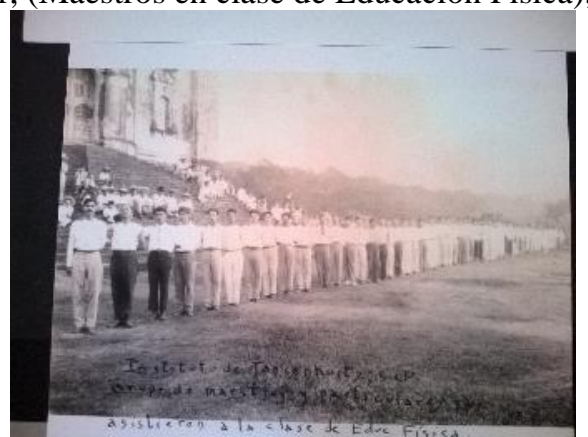

Fuente: Original conservado en el Archivo Histórico de la Secretaría de Educación Pública.

Figura 30: Sin autor, (Pirámide humana masculina), 1928, Reproducción.

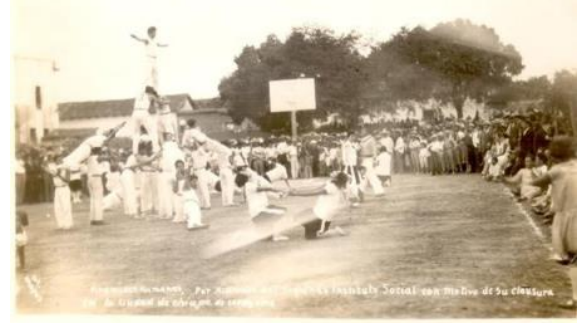

Fuente: Original conservado en el Archivo Histórico de la Secretaría de Educación Pública. 
Figura 31: Sin autor, (Maestras es gimnasia plástica), 1928, Reproducción.

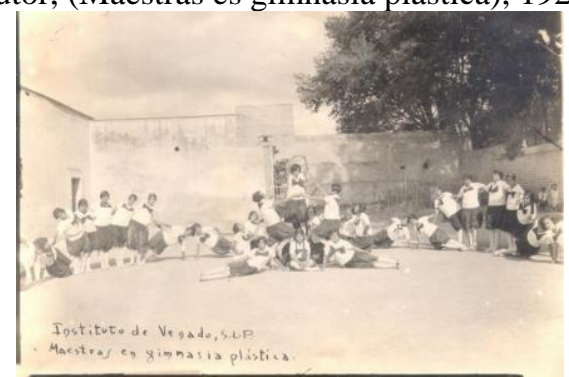

Fuente: Original conservado en el Archivo Histórico de la Secretaría de Educación Pública.

Figura 32: Sin autor, (Formación femenina y un hombre), 1927, Reproducción.

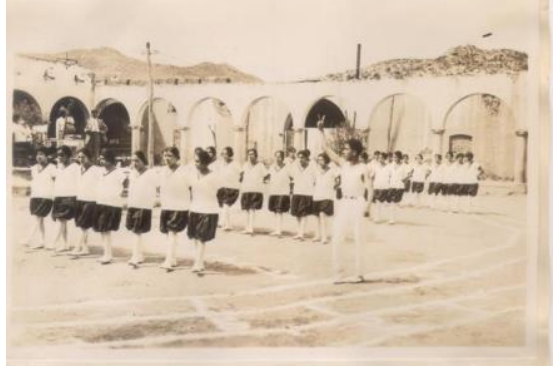

Fuente: Original conservado en el Archivo Histórico de la Secretaría de Educación Pública.

\section{Ficha Explicativa: Durango, Durango (Formación femenina con un hombre)}

A partir de 1926, con la suspensión de cultos, las guerrillas cristeras proliferaron de manera considerable a nivel nacional, diezmando a la población económica y socialmente; el gobierno estatal se vio imposibilitado para resolver dichos problemas. Tres años más tarde, el clero cedió ante las presiones por lo que los cultos se reinstauraron, pero el Estado limitó el poder de la Iglesia y sus aliados. La élite posrevolucionaria, continuó dominando, aun cuando sus propiedades se vieron fragmentadas y un nuevo ordenamiento agrario se implantara.

Figura 33: Sin autor, (Formación masiva), Sin fecha, Reproducción.

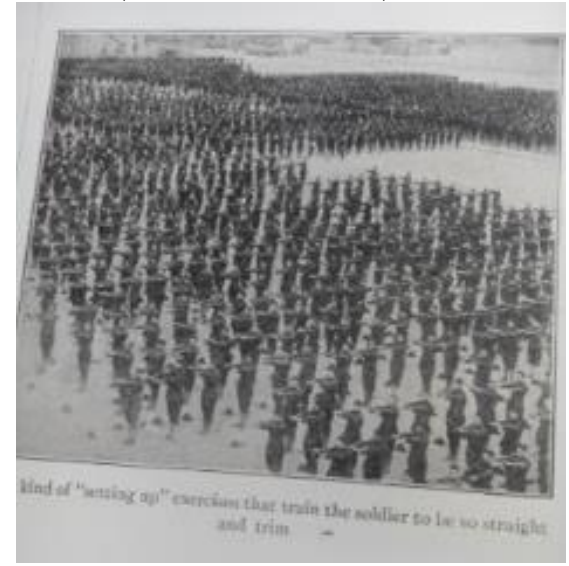

Fuente: Original conservado en Colección Particular.

Rev. Iberoam. Patrim. Histórico-Educativo, Campinas (SP), v. 4, n. 1, p. 144-169, jan./jun. 2018 


\section{CONCLUSIONES}

En cuanto a las repercusiones de esta exposición, una primera a destacarse, es que la información recabada en un proceso de investigación académico, tuvo una salida comunicativa de divulgación a públicos más amplios que sólo a colegas especialistas trascendiendo la vía tradicional en este ámbito de publicaciones de libros y textos y generando otra herramienta de corte didácticovisual.

Por otra parte, la exposición tuvo una itinerancia en el estado de San Luis Potosí en México, lo cual expandió en el tiempo y en el espacio la exhibicion de estas imágenes y la divulgación de esta investigación.

En lo referente a limitaciones, los propios deterioros de los materiales originales al paso del tiempo entorpecen su apreciación visual y esto se vincula con la precariedad de políticas de conservación de los acervos y la puesta en acceso publico de los originales. Otra limitante es que siempre será insuficiente la difusión social para generar audiencias para este tipo de eventos, puesto que no tienen la popularidad que otro tipo de eventos recreativos. Las exposiciones de este corte, suelen ser poco visitadas y es un reto generar activaciones sociales en torno a ellas para acercarlas a más personas.

La exposición fotográfica que aquí se presenta permite revalorar la importancia que jugó la introducción de una disciplina escolar en la construcción de las representaciones de género en el tránsito del siglo XIX al XX. Las fotografías sin duda nos permiten ver la manera en que la escuela fue moldeando subjetividades que reforzaban ciertos comportamientos de mujeres y hombres a través de técnicas corporales. También permiten visualizar la manera en que se construyó cotidianamente el poder político estatal mediante comportamientos, manuales, objetos, rutinas y rituales corporales en las escuelas. Todas estas prácticas y discursos fueron materializadas en su momento a través de fotografías e imágenes que en esta exposición se montaron para dar sentido a un discurso narrativo coherente desde una lectura presente del pasado. Esta exposición activó el valor testimonial de lo fotográfico no sólo por su resolución fiel y nítida de lo real, sino porque permitió asociaciones con otras significaciones que están connotadas en la imagen, es decir, que no son aparentes. Es necesario señalar que este ejercicio fue producto de un abordaje interdisciplinario que se logró a través de conjugar la investigación histórica y la contemplación 
atenta desde la historia del arte y el uso de una de sus salidas comunicativas: las exposiciones fotográficas.

Pensar en las fotografías históricas de la educación como parte del patrimonio cultural intangible de una sociedad resulta más que pertinente dado las potencialidades que las imágenes de este tipo nos ofrecen: nos permiten observar prácticas y discursos vinculados a procesos históricos específicos -en este caso con la introducción de la educación física como disciplina escolar-, también logran activar la memoria colectiva que posibilita la reflexión crítica del presente y el entendimiento de las identidades sociales, y finalmente posibilitan procesos pedagógicos al fortalecer la enseñanza y difusión de la Historia de la Educación así como la formación de profesionistas en el campo educativo. Finalmente es necesario enfatizar en la importancia que juegan los archivos institucionales en el resguardo, rescate y difusión de este material que sin duda forma parte del patrimonio histórico de la educación.

\section{BIBLIOGRAFÍA}

BARTHES, Roland, La cámara lúcida, Barcelona, Gustavo Gili, Barcelona. 1982 (póstumo)

BAXANDALL, Michael. Modelos de Intención. Sobre la explicación Histórica de los Cuadros. Madrid: Hermann Blume, 1989.

BENJAMIN, Walter. La obra de arte en la época de su reproductibilidad técnica. En:

Discursos Interrumpidos I. Madrid: Taurus, 1971.

CHÁVEZ, Mónica. Construyendo la nación y el género desde el cuerpo: la educación física en el México posrevolucionario. Desacatos, Centro de Investigación y Estudios Superiores en Antropología Social, número 30, p. 43-58, mayo-agosto 2009.

Entre el nacionalismo y la redención campesina: La difusión de la educación física en el medio rural a través de las Misiones Culturales en San Luis Potosí. Em: Oresta López (coord.). La investigación educativa en San Luis Potosí: Lente, espejo y propuesta para el cambio. San Luis Potosí, Polo Académico de San Luis Potosí A.C., Secretaría de Educación del Gobierno del Estado, Universidad Autónoma de San Luis Potosí, El Colegio de San Luis, 2009. p. 271-284.

Los orígenes de la educación física en México. Reflexiones sobre el cuerpo, el género y la nación. México, Colección Maestros e Investigaciones. Red de Investigadores Educativos de San Luis Potosí, Benemérita y Centenaria Escuela Normal del Estado de San Luis Potosí, Universidad Nacional Autónoma de México, 2009. 
ESCOLANO, Agustín; MARTI, Cristina; OSSENBACH Gabriela. El patrimonio históricoeducativo y la enseñanza de la historia de la educación. Madrid, Cuadernos de Historia de la Educación. Sociedad Española de Historia de la Educación, 2009.

GLEADOWE, Teresa. Involucrándose con el arte contemporáneo: algunas reflexiones acerca de la capacitación curatorial. Seminario de Administración de museos. Los museos de cara al siglo XXI. Memorias, Ciudad de México British Council/CONACULTA-INAH-INBA/Universidad Iberoamericana, p. 33-39, 2003.

HANNERZ, Ulf. Cultural complexity. Studies in the Social Organization of Meaning. New York: Columbia University Press, 1992.

HERNANDEZ, Francisca. 5.4. La museología crítica. En: HERNANDEZ, Francisca Planteamientos teóricos de la museología. Asturias: Ediciones Trea, 2006.

LOYO, Engracia. Gobiernos revolucionarios y educación popular en México, 1911-1928, México: El Colegio de México, 1999.

OSSENBACH, Gabriela. Manuales escolares y patrimonio histórico educativo. Education Siglo XXI, vol. 28, no. 2, p. 115-132, 2010.

PUIG, J.M. El esfuerzo educativo en México. La obra del gobierno federal en el ramo de educación pública durante la administración del presidente Plutarco Elías Calles (1924-1928). México, Publicaciones de la Secretaría de Educación Pública, tomo 1, 1928, p. 264.

RAMÍREZ, Rafael. Historia, orígenes y tendencias de las Misiones Culturales. Éxitos y fracasos. Breve análisis de las causas. México: Publicaciones de la SEP, 1927.

RISSEEUW, Carla. 8. Filming that which has no words and the issue of the public. En METJE Postma; CRAWFORD Peter I. (eds.), Reflecting Visual Ethnography -using the camera in anthropological research-, Leiden, Højberg, CNWS Publications / Intervention Press, 2006.

ROCKWELL, Elsie. La escuela cotidiana. Fondo de Cultura Económica, México, 1995.

RONSENBLUM, Naomi, A World history of photography, New York, Abbeville Press Publishers, 1981.

SIERRA, Augusto. Las Misiones Culturales, México, Sepsetentas n. 113, Secretaría de Educación Pública, 1973.

SUAZO, Félix. El (sano) oficio de curar. Estilo, Caracas, n. 33, año 9, 2003.

VAUGHAN, Mary Kay. La política cultural en la revolución. Maestros, campesinos y escuelas, 1920-1940. México: SEP, FCE, 2000. 
VELASCO, Honorio. La cultura como patrimonio. Lo material y lo inmaterial en la cultura. En ESCOLANO, Benito (ed.). La cultura material de la escuela. En el centenario de la Junta para la Ampliación de Estudios, 1907-2007. Berlanga de Duero, Soria: CEINCE, 2007. p. 29-43. 